\title{
A Literature Review for the Influence of Hierarchical Identity on Symbolic Consumption
}

\author{
Yang Wang ${ }^{1}$, Yang Feng ${ }^{1} \&$ Jie Lin ${ }^{1}$ \\ ${ }^{1}$ School of Economics, Central University of Finance and Economics, Beijing, China \\ Correspondence: Yang Wang, School of Economics, Central University of Finance and Economics, Beijing, \\ China. E-mail: wyorient@163.com
}

Received: December 22, 2021

Accepted: January 20, 2022

Online Published: January 26, 2022

doi:10.20849/abr.v7i1.985

URL: https://doi.org/10.20849/abr.v7i1.985

\begin{abstract}
Consumption is an important part of economic development, and households' cognition and emphasis on the social hierarchy affect the total amount, types and styles of consumption significantly. This paper summarizes the social significance of commodities, the development of social hierarchy with the corresponding psychology of consumption, and the cause and purpose of individual's conspicuous consumption. This paper highlights the importance of the relationship between social hierarchy and households' consumption, and provides a useful reference for understanding consumers' psychology.
\end{abstract}

Keywords: social hierarchy, symbolic consumption, conspicuousness consumption

\section{Introduction}

Consumption is a substantial part of economic development and routines for individuals. Households' consumption is the core component of the country's total consumption demand and an important driving force of economic growth from the macroeconomic perspective, and it is also related to the happiness and utility of the family from the microeconomic perspective. The objects of consumption are mainly goods and services, which are gradually changed with the different phases of economic development and social advancement. Generally, the objects of consumption are mainly focuses on industrial products when households' income is at the relatively low level, and people would upgrade both the quality and the objects of consumption as the economy develops into the higher phase. Individuals would increase the consumption on multi-type and personalized goods and service when they have abundant wealth, which is consistent with the theory of Maslow's hierarchy of needs.

When consumption becomes the main activity in the society, it means that we have entered the consumer society and people would convince the value that consumption is dominating (Zheng, 2016). Baudrillard (1986) believes that abundance is the principal feature of consumer society. For instances, China has already entered the consumer society phase as the population of the middle class approaches nearly 300 million (Zhang, 2018). Zheng (2016) think that people consume for the sake of consumption in the modern consumer society. Taking a positive view, consumption promotes economic development and social progress according to stimulating innovation, increasing employment opportunities and promoting the improvement of households' living standards.

People have various desire to flaunt, while it restricted by their ability, status and strength, therefore different groups have distinct hierarchical characteristics on the consumption style. In the conspicuous consumption, individuals' motivation is showing their outstanding identity and proving their prominent status. When the group has the sense of independence, it would try to establish the difference with other groups by holding specific objects and form the behavior of identity building, which resulting the hierarchical characteristics originating from the purpose of conspicuousness and the group characteristics different from other groups. At this point, consumption makes a profound impact on the social hierarchical stratification and group division, and gives the meaning of symbol value for the commodities, which is secretly linked to the identity and wealth. We think that the study for the influence of social hierarchy on consumption is a meaningful work for sociology and economics. 


\section{The Hierarchical Symbol of Commodities}

The development of human civilization promotes the continuous progress of social productivity, the spread of scale production and the upgrading of industrial technology have reduced the marginal production cost remarkably, which alleviated the scarcity of commodities effectively. It enables the once exclusive products owned by the aristocrats to be widely afforded or even been daily necessities among ordinary people, e.g., jellies, porcelains and vehicles. Nonetheless, the relative scarcity is still existed in varying degrees. Brock (1968) presents that the scarcity degrees of commodities are proportional to their attractiveness to consumers. He considers that scarce commodities have to satisfy three conditions: commodities could be exchanged, consumers have potential willingness to pay, and commodities have value in use and meet consumers' expectation. Miller (2009) argues that the key of consumption is self-presentation rather than owning commodities. The rich tend to manifest their wealth and status according to possessing scarce commodities, which could distinguish themselves with the ordinary obviously. Hence, merchants usually produce the commodities that highlighting high status to appeal wealthy consumers in terms of material, craftsmanship, limited edition and so on. Lynn (1989) and Lynn and Bogert (1996) find that scarce commodities that are not accessible easily have the "assumed expensiveness" to consumers. In other words, scarcity not only makes commodities difficult to obtain, but also raises consumers' evaluation on the commodities and bind the corresponding social status with their owner. Veblen (1994) expound the characteristics of expensive goods in leisure hierarchy theory. He supposes that when the consumption cost of a commodity is larger than similar normal commodities, the commodity would have additional honor attributes, and its brand represents higher social status. Consumers purchase these commodities to meet their purpose of unfairness indirectly, and the indirect utility gives a lot of value to "high-quality" commodities. The phenomenon that the demand for a commodity raises with the increase of the price is also known as Veblen effect. McCracken (1988) believes that the aristocratic lifestyle in the history has popularized the culture of exquisite and luxurious consumption, because the aristocracy has rare and expensive commodities and distinguish their different social status through luxury goods.

Consumption theory assumes that the utility and preference of individuals are independent and are not affected by the outsiders. However, consumers interact with each other and take herd mentality. Nowadays, people rely on getting information online, which is exploited by merchants and medias through consumption-oriented information. According to creating consumption concepts to consumers, they transmit the idea of "symbolic consumption", the owing commodities represent your taste, wealth and status, in order to stimulate purchasing desire. The "positional goods" discussed by Hirsch (1976) is based on this consumer psychology, and the core value of status commodities is reflecting the status of the owner. What consumers purchase is not only the value in use, but also the hierarchical symbol and inner satisfaction contained in the commodities. At the same time, media reports tend to focus on the lifestyle of top $20 \%$ high-income groups and label it as "upper class" and "advanced", thus making other groups yearning and imitating, so as to achieve the purpose of consumption orientation. The psychology has been demonstrated by Conniff (2004), whose research shows that both mammals and humans have a tendency to imitate the peers with high status, which is the reason why people imitate the behaviors of high consumption.

Income and consumption are both important to hierarchical identity. Income is the source, and consumption is the embodiment. Therefore, consumption could be regarded as an extension of economic status (Wang, 2011). In some situation, there is an unequal relationship between professional income and social status, which indicates that the people have high income while relatively low occupational prestige. They are anxious to obtain the expected social status, and make effort to compensate the lack of social prestige and status through consumption periodically (Mills, 1951). With the acceleration of modernization, the material and resource have been plentiful, and the constraints on consumers are also relaxed. People could purchase commodities and integrate them in life by their preferences. At this viewpoint, consumption decision is equivalent to the choice on lifestyle, while the key factor is still economic condition. Bourdieu (1984) highlights that lifestyle is related to the habit, taste, and economic condition of each social hierarchy, which implies the choice on commodities reflect the taste and preference as well as social hierarchy and income level of the owner.

\section{Hierarchical Identity and Symbolic Consumption}

Veblen (1994) introduces that individual identity could be presented through consumption, which illustrates that the symbolic value of commodities drives consumers' purchasing behavior. Consumption has the function of ascertaining attributions of relevant hierarchy and group. For example, when meeting strangers at the first time, people's appearance impresses their categories, attributes and social identities to the outside (Goffman, 1968). Each symbolic consumption reflects personal taste, personality, identity and status unintentionally (He, 2020). $\mathrm{Yu}$ and $\mathrm{Yu}$ (2020) emphasize that commodities are symbols that mirroring consumers themselves, and individual 
choices on consumption show the compromise between internal selfhood and external performance. Lyu (2020) argues that due to social hierarchy would be redefined as social revolution deepens, the middle class would increase symbolic consumption to show their capability and taste, in order to avoid the decline of their social status. Zhao and Tang (2019) observe that consumption affects the hierarchical identity of urban residents significantly, the proportion of survival consumption expenditure is negatively correlated with hierarchical identity, while the proportion of housing quality and development consumption expenditure is positively correlated with hierarchical identity, which indicates symbolic consumption is a critical factor of hierarchical identity.

The society and culture jointly determine the symbolic value and of commodities, and individuals usually increase symbolic consumption to obtain hierarchical identity following social and cultural custom (Wang, 2011). The value of commodities has exceeded the value in use and value in exchange in the modern consumer society. Symbolic consumption and its ideology have been the core of contemporary consumer culture (Chen, 2006). Individual hierarchical identity is affected by her consumption gradually, and consumption has been a substantial dimension of social stratification (Sun et al., 2012).

In addition, social exclusion may lead to the occurrence of symbolic consumption. When individuals are threatened under social exclusion, they are afraid to lost their dignity and status. In order to eliminate adverse psychological effects, individuals try to return the original group, or search a new group that could accept them. The excluded usually increase symbolic consumption to achieve their goals due to commodities have signal attribute (Berger and Health, 2007). It indicates that consumers believe the unsatisfactory situation they face could be changed through appropriate symbolic consumption. Personality and social psychology play important role in the process. People usually hope to maintain appropriate self-esteem to protect themselves when they are excluded (Tesser, 1988). Brockner (1983) thinks that people with low self-esteem are more likely to be influenced by the outside than those with high self-esteem. Mead et al (2011) provide that when individuals are excluded, they would change their preferences in order to be accepted by the group and purchase impractical commodities symbolize the membership of the group, in order to regain social network. Lee and Shrum (2012) further present that when individuals perceive they are excluded by the group invisibly, they tend to purchase commodities with larger brand logo, that is a specific form of symbolic consumption, conspicuous consumption.

\section{Hierarchical Identity and Conspicuous Consumption}

Rational consumption is the common form of consumption choice, which could be regarded as self-discipline on consumption, which is under the resource constraints of individuals and families. Accordingly, perceptual consumption indicates that people choose commodities following the perceptual principle. Due to the existence of resource constraints, individuals have to make the reasonable arrangements for the utility maximization, which causes the repression of perceptual consumption (Wang, 2011). Sometimes the commodity is more popular as the price is higher, because consumers are concerned the conspicuous behavior rather than the value in use, in order to show their status and meet the vanity psychology (Qin, 2019). Miller (2009) argues that consumerism makes two illusions for consumers to stimulate consumption: some commodities could enhance personal traits and cover individual defects in social communication; and personal traits shown through commodities are more attractive than natural characteristics. O'Cass and McEwen (2004) distinguishes the difference between status consumption and conspicuous consumption. He argues that individuals consume status consumption to purchase commodities with status implication to fit their self-identity and orientation, they would not present these commodities to the people with higher status to improve their social status. While people concern how to display or show the products in front of others by means of conspicuous consumption, and they take the brand value-added of commodities as the symbol of wealth and status in order to elevate their status. Charles et al. (2009) emphasize that tangible consumption depends on whether the consumption could help to improve others' judgment on consumers' income, and they would reduce consumption if the consumption damage their image.

Marcoux et al. (1997) observe that interpersonal interaction is a considerable reason that people have conspicuous consumption. When individuals wish to close the group with higher social hierarchy, they would imitate similar lifestyle of the target group through conspicuous consumption (Trigg, 2001). Duesenberry (1949) thinks that households' consumption has strong pattern of social interaction, including imitation and demonstration, such as consumers with relatively low income tend to imitate and pursue the consumption behavior of surrounding groups with higher income. Liu and Zhu (2020) provide that conspicuous consumption sends the signal of family's social status, which transmits the information about their consumption ability to the groups around them. People evaluate others' social hierarchy by subtle clues, and hierarchical identity influences social interaction substantially (Guo and $\mathrm{Fu}, 2019$ ). As people widely regards the value of commodities held by 
others as a significant reference for their capacity, individuals also could get the opportunity to have complementary communication with the groups with higher status by conspicuous consumption (Rege, 2008). When individuals are excluded in the social interaction, they may think that their status are threatened and lower their self-identity, which also leads to conspicuous consumption and other bad consumption behaviors (Lee and Shrum, 2012). Nelissen and Meijers (2011) find that due to presenting luxury commodities are regarded as expensive signals, therefore purchasing luxury commodities have been an available social strategy, which takes intangible benefits to specific consumers. For example, the groups with high consumption are often considered to have better capacity and higher wages.

In some cases, vulnerable groups also have conspicuous consumption. Charles et al. (2009) show that the black and Hispanic spend nearly $30 \%$ more than the white on clothes, jewelry, vehicles and personal care items, which indicates that they consider conspicuous consumption as invisible signals of income and status. Bloch et al. (2004) observe that wedding spending is proportional to the audience's perception on the family status of the newlyweds in rural India. In order to explain why vulnerable groups tend to show wealth irrationally, Sivanathan and Pettit (2010) introduce the viewpoint of compensation psychology, which illustrates conspicuous consumption is a compensatory behavior aimed at restoring self-esteem and healing psychological pain and negative emotions.

\section{Conclusion}

This paper reviews the relationship between hierarchy identity and symbolic consumption from three angles. First of all, except the value in use, the value of commodities is also endowed with specific symbolic value in the sociology, which conveys the signals of consumers' identity and status to others subtly, and the symbolic consumption is regarded as an extension of economic status. Secondly, people believes that there are corresponding relationships between hierarchy identity and consumption pattern, which leads individuals to adjust their consumption expenditure and structure after perceiving the possible change of own hierarchy. Due to the commodities have the signals of symbol, people usually take them as the signs of hierarchy identity, and sometimes seek back to the target groups through purchasing specific commodities. At last, consumers may have irrational conspicuous consumption to show their economic capacity and social status through conspicuous consumption, in order to create an ideal social image to meet their psychological identity.

Generally speaking, as a substantial economic activity, consumption reveals plenty personal patterns and purposes, which is worthy of paying attention on the relationship between hierarchical identity and consumption, especially for the possible mechanisms. There should have further discussion to complement current theoretical structure.

\section{References}

Baudrillard, J. (1986). La société de consummation. Paris: Gallimard.

Berger, J., \& Heath, C. (2007). Where consumers diverge from others: Identity-signaling and product domains. Journal of Consumer Research, 34(2), 121-134. https://doi.org/10.1086/519142

Bloch, F., Vijayendra, R., \& Sonalde, D. (2004). Wedding Celebrations as Conspicuous Consumption: Signaling Social Status in Rural India. The Journal of Human Resources, 39(3), 675-695. https://doi.org/10.2307/3558992

Bourdieu, P. (1984). Distinction: A Social Critique of the Judgement of Taste. Cambridge: Harvard University Press.

Brock, T. C. (1968). Implications of Commodity Theory for Value Change. Psychological Foundations of Attitudes, 243-275. https://doi.org/10.1016/B978-1-4832-3071-9.50016-7

Brockner, J. (1983). Low self-esteem and behavioral plasticity: Some implications. Review of personality and social psychology, 4, 237-271.

Charles, K. K., Hurst, E., \& Roussanov, N. (2009). Conspicuous consumption and race. The Quarterly Journal of Economics, 124(2), 425-467. https://doi.org/10.1162/qjec.2009.124.2.425

Chen,Y. (2006). Commodity symbols and symbol consumption. Zhejiang Social Sciences, 6, 137-141, 150. (in Chinese)

Conniff, R. (2004). The natural history of the rich. New York: W. W. Norton \& Company.

Duesenberry, J. S. (1949). Income, saving, and the theory of consumer behavior. Cambridge: Harvard University Press. 
Goffman, E. (1968). Stigma: Notes on the Management of Spoiled Identity. Harmondsworth: Penguin.

Guo, R., \& Fu, X. (2019). Social class signs and their effects on interpersonal social interactions. Advances in Psychological Science, 27(7), 1268-1274. https://doi.org/10.3724/SP.J.1042.2019.01268. (in Chinese)

He, A. (2020). Symbolic consumption: the way of identity Construction in Modern Society. Modern Business, 10, 9-10. (in Chinese)

Hirsch, F. (1976). Social Limits to Growth. Cambridge: Harvard University Press. https://doi.org/10.4159/harvard.9780674497900

Lee, J., \& Shrum, L. J. (2012). Conspicuous consumption versus charitable behavior in response to social exclusion: A differential needs explanation. Journal of Consumer Research, 39(3), 530-544. https://doi.org/10.1086/664039

Liu, Q., \& Zhu, X. (2020). The Difference Between Urban and Rural Conspicuous Consumption and Social Status Seeking. Shanghai Management Science, 42(2), 44-50. (in Chinese)

Lynn, M. (1989). Scarcity Effects on Desirability: Mediated by Assumed Expensiveness?. Journal of Economic Psychology, 10(2), 257-274. https://doi.org/10.1016/0167-4870(89)90023-8

Lynn, M., \& Bogert, P. (1996). The Effect of Scarcity on Anticipated Price Appreciation. Journal of Applied Social Psychology, 26(22), 1978-1984. https://doi.org/10.1111/j.1559-1816.1996.tb01783.x

Lyu, Q. (2020). The psychological anxiety of the middle class and the difficulty of symbol consumption. Social Science Journal, 4, 115-121. (in Chinese)

Marcoux, J., Filatrault, P., \& Chéron, E. (1997). The Attitudes Underlying Preferences of Young Urban Educated Polish Consumers Towards Products Made in Western Countries. Journal of International Consumer Marketing, 9(4), 5-29. https://doi.org/10.1300/J046v09n04_02

McCracken, G. (1988). Culture and Consumption. Bloomington: Indiana University Press.

Mead, N. L., Baumeister, R. F., Stillman, T. F., Rawn, C. D., \& Vohs, K. D. (2011). Social exclusion causes people to spend and consume strategically in the service of affiliation. Journal of Consumer Research, 37(5), 902-919. https://doi.org/10.1086/656667

Miller, G. (2009). Spent: Sex, Evolution, and Consumer Behavior. New York: Viking.

Mills, C. W. (1951). White Collar: The American Middle Classes. New York: Oxford University Press. https://doi.org/10.1007/978-1-349-23771-5_11

Nelissen, R., \& Meijers, M. H. C. (2011). Social benefits of luxury brands as costly signals of wealth and status. Evolution and Human Behavior, 32(5), 343-355. https://doi.org/10.1016/j.evolhumbehav.2010.12.002

O’Cass, A., \& McEwen, H. (2004). Exploring consumer status and conspicuous consumption. Journal of Consumer Behaviour, 4(1), 25-39. https://doi.org/10.1002/cb.155

Qin, P. (2019). The problem of conspicuous consumption and the restraint of it. Chinese Social Sciences Today. (in Chinese)

Rege, M. (2008). Why Do People Care about Social Status?. Journal of Economic Behavior \& Organization, 66(2), 233-242. https://doi.org/10.1016/j.jebo.2006.04.005

Sivanathan, N., \& Pettit, N. C. (2010). Protecting the self through consumption: Status goods as affirmational commodities. Journal of Experimental Social Psychology, 46(3), 564-570. https://doi.org/10.1016/j.jesp.2010.01.006

Sun, F., Zhang, Y., \& Xiao, J. (2012). On the Consumer Behavior of the Status Consumption. Journal of Shandong University (Philosophy and Social Sciences), 3, 16-23. (in Chinese)

Tesser, A. (1988). Toward a self-evaluation maintenance model of social behavior. Advances in experimental social sychology, 21, 181-228. https://doi.org/10.1016/S0065-2601(08)60227-0

Trigg, A. B. (2001). Veblen, bourdieu, and conspicuous consumption. Journal of Economic Issues, 35(1), 99-115. https://doi.org/10.1080/00213624.2001.11506342

Veblen, T. (1994). The Theory of the Leisure Class. New York: Dover Publications. (Original work published in 1899).

Wang, N. (2011). The sociology of consumption. Beijing: Social Sciences Academic Press. 
Yu, H., \& Yu, W. (2020). How consumption shapes individual identity. People's Tribune, 16, 70-71. (in Chinese)

Zhang, Y. (2018). Opportunities and challenges that must be faced squarely in social transformation, development and social governance. Beijing Daily. (in Chinese)

Zhao, W., \& Tang, P. (2019). Study on the Impact of Consumption on the Middle-class' Self-identification in Urban China-Based on the Data of CSS 2013. Journal of Harbin Institute of Technology (Social Sciences Edition), 21(5), 63-69. (in Chinese)

Zheng, Y. (2016). The advent of the post-materialistic era. China CITIC Press.

\section{Copyrights}

Copyright for this article is retained by the author(s), with first publication rights granted to the journal.

This is an open-access article distributed under the terms and conditions of the Creative Commons Attribution license (http://creativecommons.org/licenses/by/4.0/). 